\title{
Considering the Future of Water Resources: A Call for Investigations that Include the Cultural Anthropology of Water
}

\author{
Jason A Hubbart ${ }^{1,2 *}$ \\ ${ }^{1}$ Davis College of Agriculture, Natural Resources \& Design, West Virginia University, USA \\ ${ }^{2}$ Institute of Water Security and Science, West Virginia University, USA
}

Submission: February 16, 2018; Published: March 26, 2018

*Corresponding author: Jason A Hubbart, Davis College of Agriculture, Institute of Water Security and Science, Natural Resources \& Design, West Virginia University, Morgantown, WV, USA, Tel: +01-304-293-2472; Email: Jason.Hubbart@mail.wvu.edu

\begin{abstract}
Water resources have served as the basis for war and the facilitator of peace. The control of water has been a statement of power and technological sophistication. However, control may have led to complacency in sustainable management in many locations globally. Humans must therefore reconstruct how they think about water and embrace a contemporary ethic. This short communication is intended to serve as an alert to the need for water resources investigations that include the cultural anthropological relationship with the resource. This is important because at no time in history have water resources been under such global anthropogenic pressures as at present. Human society is more complex than ever before. Brief historical context is provided, followed by examples of research challenges that should include an anthropological component. As humans enter a period of human history focused on the availability and quality of fresh water the need has never been greater to integrate water research with the human relationship with water to enlighten and improve future sustainability of the resource.
\end{abstract}

Keywords: Water; Water resources; Cultural anthropology; Water history; Water research

\section{Historical Background}

Since ancient times human civilizations have developed in locations of ample water. Lacking in modes of modern transportation, early cultures needed to locate in close proximity to rivers, streams, lakes, oceans and seas. Given the importance of water for everything ranging from drinking water to conveyance and commerce, hydrologic information was vital to early civilizations. Increased understanding was necessary to increased control of the resource. For example, the flow rates and yields of rivers were monitored by the Egyptians as early as 3800 years ago, and rainfall measuring instruments were first utilized approximately 2400 years ago. The concept of a global hydrologic cycle dates back at least 3000 years when early Greek philosophers including Thales, Anaxagoras, Herodotus, Hippocrates, Plato, and Aristotle conceptualized the basic processes. With advanced knowledge came greater abilities to control water through engineering. King Scorpion of Egypt (approximately 3200 B.C.) was shown in a painting to "cut the first sod" of an irrigation ditch. In approximately 1950 B.C. the Nile River and the Red Sea were connected by a navigational canal during the reign of Seostris I, and the Romans (approximately 100 B.C. to 200 A.D.) built massive aqueducts [1,2]. In the seventeenth century, the modern scientific approach to studying the hydrologic cycle was initiated by the Frenchmen Pierre Perault and EdmeMarriotte [3]. By the 1670's and 1680's, they had published data and calculations that showed conclusively that precipitation was the precursor to stream flow. By 1700 , Edmund Halley estimated the quantity of water involved in the hydrologic cycle of the Mediterranean Sea and surrounding lands. Substantial progress was made during the eighteenth century in applications of mathematics, fluid mechanics, and hydraulics by scientists like Pitot, Bernoulli, Euler, Chezy, and other European professionals. The term "hydrology" was adopted around 1750, and by 1800 the work of English physicist and chemist John Dalton solidified the current understanding of the global hydrologic cycle. The first half of the twentieth century saw great advancements in the hydrological sciences starting with the addition of the Section of Scientific Hydrology in the International Union of Geodesy and Geophysics in 1922. This was followed by the addition of the Hydrology Section of the American Geophysical Union in 1930 [1,4]. These were the first formal recognitions of the scientific status of hydrology. Many scientists have contributed substantially to hydrologic disciplines since that time and countless discoveries are detailed in the scientific literature. However, while humans have learned 
to engineer water, there remains a great need to discover longterm sustainable solutions to decisively advance management.

This short communication is intended to serve as an alert for the great need for objective investigations in water resources that include the cultural anthropological relationship with and subsequent future management of the resource. This is important because at no time in history have water resources been under such global anthropogenic pressures as at present. Human society is more complex than ever before. The demands for fresh water resources are greater than any time in history. As we enter a period of human history focused on the availability and quality of fresh water the need has never been greater to reexamine the human relationship with water to enlighten and improve future sustainability of the resource.

\section{Water Resource Challenges}

There are many water resources challenges that require immediate attention, including assessing the impacts that growing populations have on water supplies, land use change on groundwater reserves, and river discharges. There is a growing need for improved understanding of pollutant related flows in surface and groundwater and the bioremediative capacities of aquifers and rivers forvarious pollutants. Studies must be conducted to better understand landscape processes including hill slope forms, channel networks and the processes responsible for transport of water, sediments, and pollutants. There is an ongoing need for improved understanding of the interactions of climate change and the hydrologic cycle. Critical questions need to be asked concerning changes observed in water availability and timing and whether specific regions can be identified where the interactions between water availability and human demand becomes problematic, or conversely where opportunities may exist for sustainable management. Additionally, the characterization and subsequent modeling of these systems is an ongoing challenge. There are a number of unresolved issues that continue to impede the ability of scientists and practitioners to analyze and predict behavioral changes of hydrological systems. One of the most predominant features of hydrological systems is the spatial heterogeneities and temporal variability's and land use legacies that occur perpetually and persistently at multiple scales. Modeling physical processes amidst such complexity is a constant challenge. It is for these reasons that theoretical upscaling and downscaling attempts to develop quantitative links among processes has been such a confounding task.

While previous practices and legacy effects [5] are clearly of anthropological interest, such information is also very telling in terms of the culture of water resources at a given time. Water has always been perceived as plentiful, and rightfully so. The planet is covered more than $70 \%$ by water. However, human population pressures are stressing the fresh water component well beyond sustainable thresholds. For perspective, in 1915 the global human population was approximately 1.8 billion relative to approximately 7.6 billion at the time of this writing. This growth in just over 100 years! Is it surprising that humans are exacting pressures on water supplies, unprecedented in history? Why are lessons of the past seemingly forgotten in many places? How is it possible that in some regions humans may have dismissed the difficult origins in the relationship with water? Examples are prolific in history of substantial engineering feats ranging from hydroelectric dams, canals and even through global exhibits such as world's fairs. Humans have thus conquered the resource through engineering and showcased that engineering progress, but perhaps become complacent and somewhat apathetic in sustainability.

\section{Forward Thinking and Closing Comments}

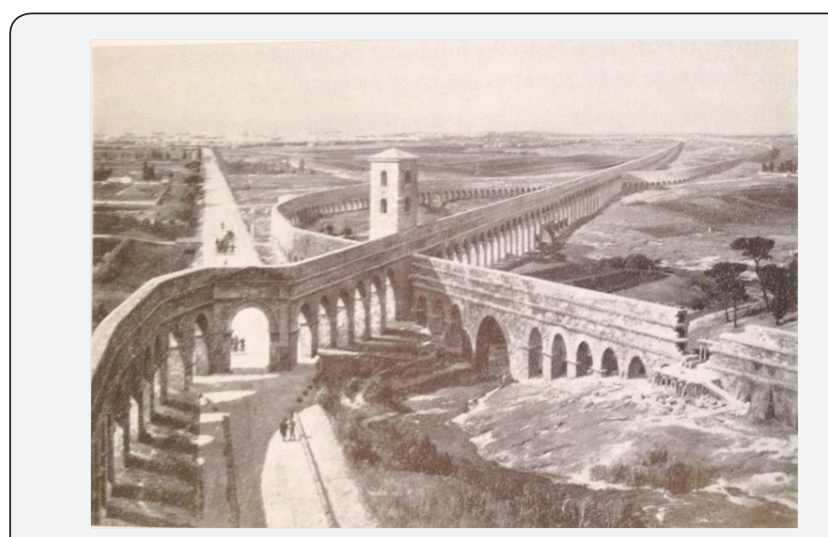

Figure 1: The Anio Novus and the Claudia aqueducts (left foreground) of Rome restored in a single structure and the Marcia, Tepula, and Julia (right). Painting by Zeno Diemer, courtesy of Deutsches Museum, Munich [1].

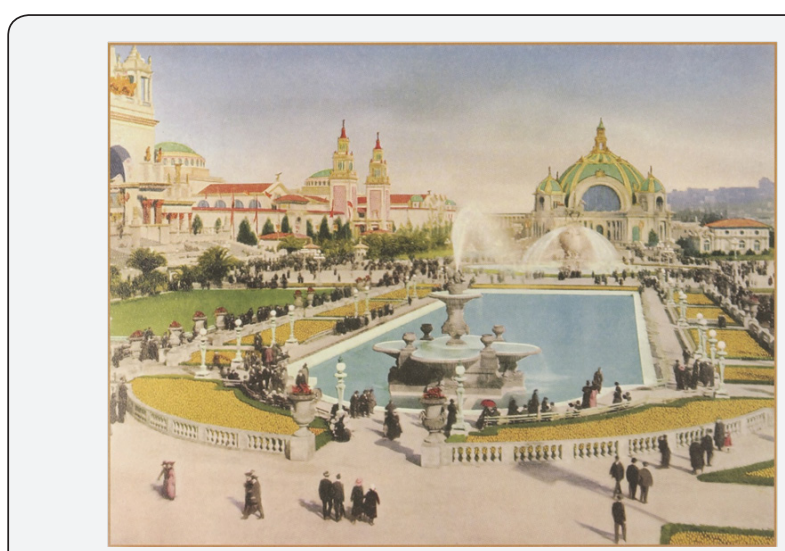

Figure 2: The South Gardens of the Panama Pacific International Exposition (PPIE). Photo courtesy of the Donald G. Larson collection on World's Fairs and Expositions, California State University Fresno Henry Madden Library, Fresno, California, USA.

Water resources have served as the basis for war and the facilitator of peace. The control of water has been a statement of power and technological sophistication, be that through the great aqueducts of Rome (Figure 1), the Panama Canal, widespread agriculture, or the great fountains of PPIE (Figure 2). Despite great feats of engineering, humans have drastically altered fresh water availability and quality. Though perhaps not 
an uncommon scarcity in all locations, water availability, for the first time in human history is becoming a long-term, globalscale problem. Current management reflects a culture of belief that water is available in nearly unlimited supplies. However, that culture is changing with population growth, agricultural expansion, pollution, urbanization and changes in historic weather patterns and local to regional shortages. There is a great need for research that investigates current management problems and the cultural anthropology of water. Perhaps if more work is conducted to understand how humans have arrived at the current state, planning forward can be more deliberate.

Ultimately, humans must reconstruct how they think about water and embrace a contemporary ethic, or a philosophy that guides actions when management decisions are applied to the resource. The idea of a water ethic is something that must be achieved and that will transcend management and regulation. Ironically, if humans are observing a water ethic there may be little to no need for regulations. An instinct must be adapted that includes the philosophy that when the quality, quantity, aesthetics and resilience of water are met humans are best managing the resource to be sustainable. An examination of water resources management of the past, challenges, and legacies of the current era can help humans (re)develop this ethic and plan more effectively for a sustainable water resources future.

\section{Acknowledgement}

This work was supported by the National Science Foundation under Award Number OIA-1458952, the USDA National Institute of Food and Agriculture, Hatch project 1011536, and the West Virginia Agricultural and Forestry Experiment Station. Results presented may not reflect the views of the sponsors and no official endorsement should be inferred. The funders had no role in study design, data collection and analysis, decision to publish, or preparation of the manuscript. Special thanks are due to many scientists of the Interdisciplinary Hydrology Laboratory (www. forh2o.net).

\section{Conflict of Interest}

The author declares that there is no conflict of interest.

\section{References}

1. Biswas AK (1970) History of Hydrology. North-Holland Publishing Company, Amsterdam- London, pp. 336.

2. Hubbart JA, Larson DG (2016) Understanding the Cultural Anthropology of Water by Investigating the History of World's Fairs: An Alert for needed Research. International Education and Research 2(7): 17-19.

3. Hubbart JA (2011) Origins of Quantitative Hydrology: Pierre Perrault, EdmeMariotte, and Edmund Halley. Special edition, Water Resources Impact 13(6): 15-17.

4. Cech TV (2010) Principles of Water Resources, History, Development, Management and Policy, ( ${ }^{\text {rd }}$ edn). John Wiley \& Sons, Inc. Hoboken, JN, USA p. 1-18.

5. Kellner E, Hubbart JA (2017) Confounded by Forgotten Legacies: Effectively Managing Watersheds in the Contemporary Age of Unknown Unknowns. Hydrological Processes.

\section{Your next submission with Juniper Publishers} will reach you the below assets

- Quality Editorial service

- Swift Peer Review

- Reprints availability

- E-prints Service

- Manuscript Podcast for convenient understanding

- Global attainment for your research

- Manuscript accessibility in different formats

( Pdf, E-pub, Full Text, Audio)

- Unceasing customer service

Track the below URL for one-step submission https://juniperpublishers.com/online-submission.php 